\title{
Settlement scale analysis approach to reach nearly zero energy communities
}

\author{
Ece Kalaycıŏglu ${ }^{1, *}$, and Ayşe Zerrin Yılmaz², \\ ${ }^{1}$ Ozyegin University, Faculty of Architecture and Design, Çekmeköy Campus, 34794, Çekmeköy, Istanbul, Turkey \\ ${ }^{2}$ Istanbul Technical University, Faculty of Architecture, Taskisla Campus, 34367, Taksim, Istanbul, Turkey
}

\begin{abstract}
Looking at the recent developments, the European Union (EU) aims to become a zero carbon community. For the building sector, Energy Performance of Buildings Directive (EPBD) was recast in 2010 introducing the definition of the nearly zero energy building (NZEB) levels to construct all new buildings at this level by the end of 2020. The last revision of the directive in 2018 also promotes the renovation of the building stock to the NZEB levels. In the paper, it was proposed to define the nearly zero energy levels for settlements. This way, it was aimed to discuss the advantages and disadvantages of reaching the nearly zero energy levels at larger scales than single buildings. Settlement level studies, including the district energy systems, intended to reveal the energy efficiency measures which lead to optimal cost levels for more than one building. Key parameters were examined for a new settlement design which may be beneficial for the large-scale renewable energy system implementation and district energy system (DES) usage with high energy performance buildings.
\end{abstract}

\section{Introduction}

Energy has been one of the key issues of all the states for financial balances, external affairs, and internal politics. European Union (EU), working on the subject since decades, has set several targets to reduce its external dependency, to secure clean energy sources, and to be a nearly zero energy community by 2050 . Target years include 2020, 2030 and 2050, and each includes the strategies for energy efficiency, renewable energy usage, and greenhouse gas emission reduction rates [1].

EU's activities objecting the building sector energy efficiency can be reviewed mainly under the directives on the energy performance of buildings. The first one was published in 2002 to set and assure the minimum energy performance requirements for both new and existing buildings [2]. Energy performance of buildings directive (EPBD) was recast in 2010 introducing new terms as cost-optimal and nearly zero energy levels for building energy performance. Relatedly, it introduced a methodology framework, cost-optimal methodology, to determine these levels. EPBD 2010 also mandated throughout the EU all new public buildings, by the end of 2018 and all new buildings, by end of 2020, to be constructed as nearly zero energy building (NZEB) [3]. Lastly, EPBD was revised in 2018 which was primarily focused on increasing the building stock renovation rate to the required energy performance levels.

The aim of this paper is to discuss the advantages and disadvantages to reach a very high energy performance at settlement scale on the road to a zero carbon community. The discussion was based on the results of a case study which includes a virtual settlement level study explained under the "3 Case Study" title and further information can be found in detail in [4].

The case study basically has two phases. First, through the building scale studies, high energy performance levels which are supported by renewable energy systems were defined. This definition was practically made by the principles of the cost-optimal methodology of EPBD 2010. Secondly, settlement scale high energy performance was assured which is affected by building locations and distances between them, street orientations, district energy system configurations, etc. The main points of the approach were explained in the Method section.

\section{Method}

In the study, the cost-optimal methodology of EPBD was proposed to be adopted to settlement level analyses, aiming to reach high energy efficiency levels, not only in buildings but also at settlement scale. Relatedly, another objective was to research the possibilities of decreasing the global costs of high energy performance levels (NZEBs) of buildings to the optimal levels (costoptimal).

As it is well-known, under the cost-optimal methodology, various energy efficiency measures (EEMs) are applied to a reference building (RB) and primary energy consumptions (PECs) are calculated or simulated for each measure. Besides, global costs (GC) of the building with each measure are calculated and PEC of the measure with the lowest GC is selected as

* Corresponding author: ece.kalaycioglu@,ozyegin.edu.tr 
cost-optimal level (CB) for that specific type of building in that specific climate type. After that phase, each nation defines the nearly zero energy levels for each building and climate type by considering the incentives, discounts, credits, etc. through their financial, social, energy politics and targets. The whole procedure is schematized in Figure 1.

As it comes to the settlement scale energy performance analyses, buildings and district energy systems (DESs) could be analysed together. Different energy levels for buildings and several district energy system alternatives can be combined for the analysis. Thus, as an energy performance indicator, primary energy consumption of the DES should be calculated or simulated. Here, it is focused on the community cost of the entire system, even the investors or managers of the buildings and DES managements are generally diversified. Community cost of the whole system includes the total investment costs of buildings and DES, cost of energy supplied from the grid and operation and maintenance costs of buildings and DES during a 20year period. Similar to the cost-optimal methodology framework, the net present value method may be used for the global (community) cost calculations. Finally, the settlement configuration with the lowest global cost can be named as the cost-optimal settlement (CS) and the configuration with higher energy efficiency can be named as the highly efficient settlement (HES).

The proposed methodology is schematized in Figure 1 below.
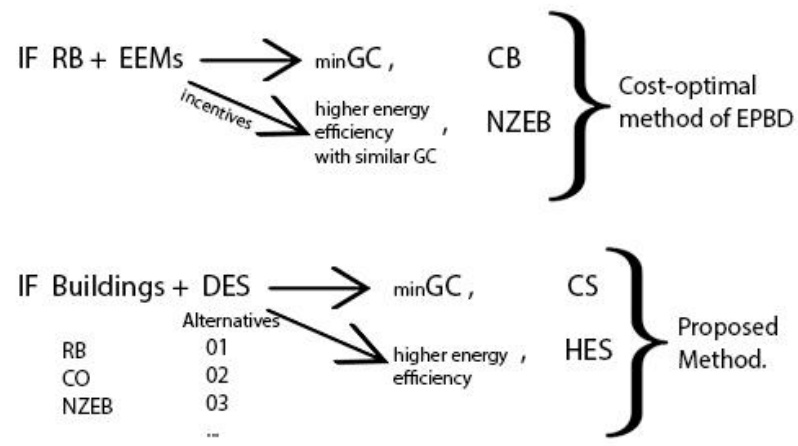

Fig. 1. Schematic explanation of the proposed method.

\section{Case Study}

In the case study, the proposed methodology was applied to a virtual newly-designed settlement in Eskişehir, Turkey. 34 Residential, 7 office and 1 light-industry building were included in the settlement and site locations were determined to optimize the solar gains for each building and to minimize the losses of the district energy system (DES) distribution network.

Reference buildings were designed to represent the existing building stock and according to Turkish national standards.

Cost optimal levels were determined by applying the cost-optimal methodology of EPBD. As nearly zero energy levels were not determined yet for Turkey, the building cost-optimal cases with renewable energy contribution were accepted as high energy performance (HEP) buildings.

DES alternatives were configured to include heating, cooling, and renewable energy systems. Thus cogeneration units (CHP), boilers, chillers, and photovoltaic panels (PVs) were utilized to constitute the alternatives.

\section{Results}

As it was asserted, the cost-optimal methodology was applied to each reference buildings to reach the specific energy performance levels of buildings, which are costoptimal and high energy performance levels. These energy performance levels will be used as demand inputs at the settlement level analyses.

The simulation results of the case study include basically both the building and settlement level primary energy consumptions, energy efficiency levels, and global costs. Building level results show the primary energy consumptions and improvement percentages for reference, cost-optimal and high energy performance levels of each building type.

Table 1. Residential building primary energy consumptions for the reference, cost-optimal and high energy performance levels.

\begin{tabular}{|l|c|c|c|}
\hline & Reference & Cost-Optimal & HEP \\
\cline { 2 - 4 } & 96.84 & 61.71 & 36.50 \\
\hline $\left.\begin{array}{l}\mathrm{PEC} \\
\text { Improvement }\end{array} \mathrm{m}^{2}\right]$ & $/$ & $36 \%$ & $62 \%$ \\
\hline
\end{tabular}

Table 2. Office building primary energy consumptions for the reference, cost-optimal and high energy performance levels.

\begin{tabular}{|l|c|c|c|}
\hline & Reference & Cost-Optimal & HEP \\
\hline $\mathrm{PEC}$ & 175.00 & 105.63 & 88.83 \\
{$\left[\mathrm{kWh} / \mathrm{m}^{2}\right]$} & $/$ & $40 \%$ & $49 \%$ \\
\hline Improvement & & $40 \%$ \\
\hline
\end{tabular}

Table 3. Light industry building primary energy consumptions for the reference, cost-optimal and high energy performance levels.

\begin{tabular}{|l|c|c|c|}
\hline & Reference & Cost-Optimal & HEP \\
\hline $\mathrm{PEC}$ & 392.34 & 231.51 & 117.10 \\
{$\left[\mathrm{kWh} / \mathrm{m}^{2}\right]$} & $/$ & $41 \%$ & $70 \%$ \\
\hline Improvement & & 4 & \\
\hline
\end{tabular}

According to Table 1, 2, and 3, the cost-optimal levels of each building type have about $40 \%$ of improvement compared to the reference cases. When it comes to the higher energy performance levels with renewable energy contribution, residential and light industry building have improvement above $60 \%$ while the office building's improvement is about $50 \%$. 


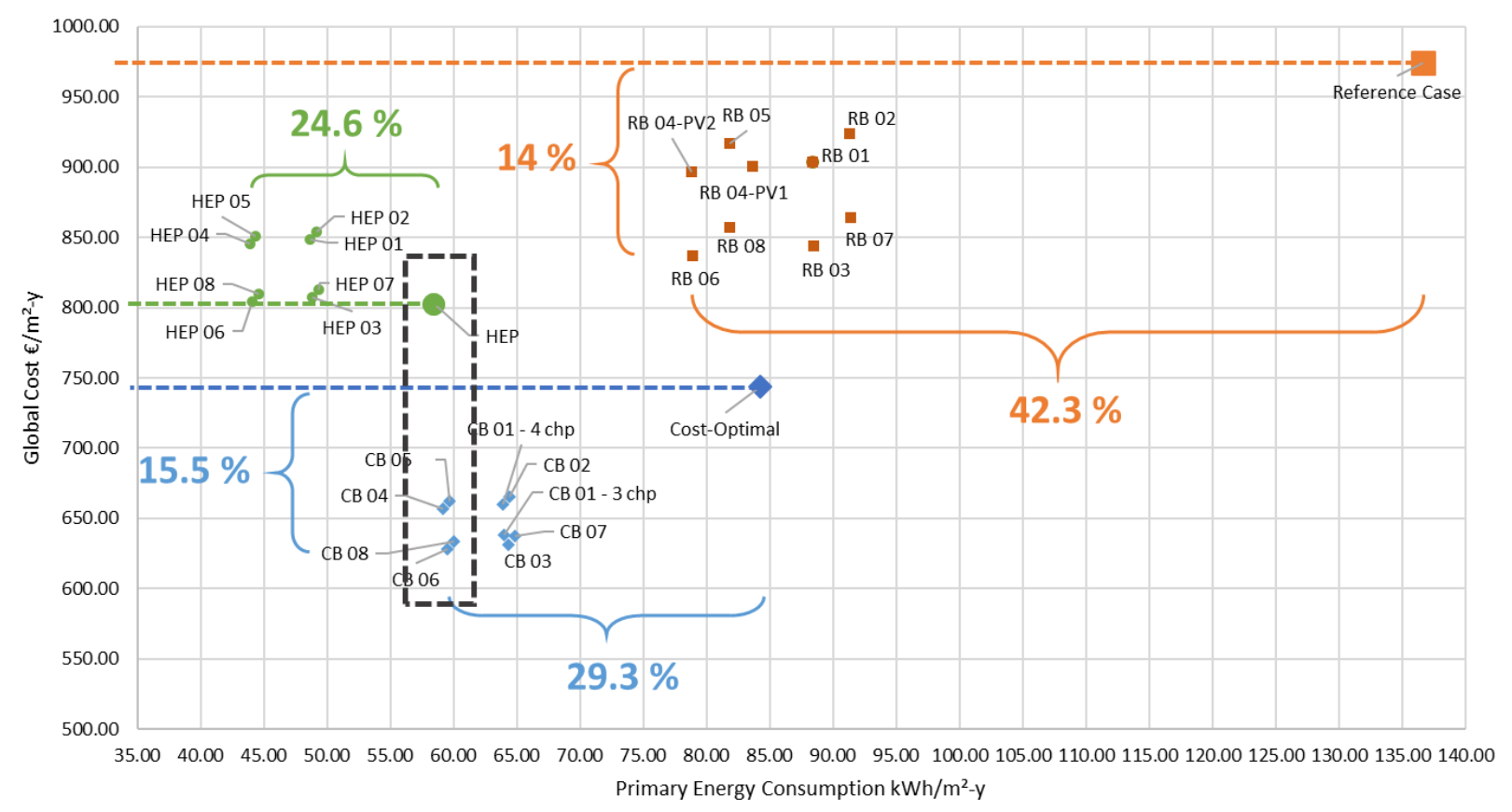

Fig. 2. Primary energy consumptions and global costs of each settlement case including reference, cost-optimal, and nearly zero energy buildings and DES alternatives.

Table 4. Buildings total primary energy consumptions for the reference, cost-optimal and high energy performance levels in the settlement.

\begin{tabular}{|l|c|c|c|}
\hline & Reference & $\begin{array}{c}\text { Cost- } \\
\text { Optimal }\end{array}$ & HEP \\
\hline $\begin{array}{l}\text { Total PEC } \\
{\left[\mathrm{kWh} / \mathrm{m}^{2}\right]}\end{array}$ & 136.68 & 84.22 & 59.11 \\
\hline Improvement & $/$ & $38 \%$ & $57 \%$ \\
\hline
\end{tabular}

Settlement scale result given in Table 4 is the aggregation result of each building in the settlement, thus it doesn't include the district energy systems. At the settlement level, cost-optimal level of buildings corresponds to $38 \%$ higher energy efficiency compared to reference buildings. This improvement ratio is $57 \%$ with high energy performance buildings.

Primary energy consumptions for all the settlement case alternatives were demonstrated together with global costs in the graph given in Figure 2. Reference (RB), cost-optimal (CB) and high energy performance (HEP) points indicate the cases without DES, which were also summarized in Table 4. It can be seen from the graph that primary energy consumptions are being able to be decreased by DES connection for each building energy performance level. However, the effectiveness of the district energy systems was also decreasing while the building energy performance level increasing. More importantly, in the cases with nearly zero energy buildings, global costs of the cases with DES alternatives were higher than the case without DES. Here, it should be asserted that only the investment costs of the district energy system transformation of the buildings were included in the global costs, but not the removal costs of the old (building-specific) system.

In Figure 2, the settlement cases with and without DES can be also examined. Comparing the case of nearly zero energy buildings without DES and the case of cost-optimal buildings with DES alternatives 6 and 8 have nearly the same primary energy consumptions. However, comparing their global costs, the cases with cost-optimal buildings have much lower global costs. This comparison is summarised also in Table 5 with some other cases. Thus, as a result, it can be asserted that connection of a settlement with cost-optimal buildings to district energy system carries the global costs to a lower level, which may be accepted as nearly zero energy level.

Table 5. Comparison of some settlement cases.

\begin{tabular}{|l|c|c|c|c|}
\hline & RB & $\begin{array}{c}\text { HEP } \\
\text { Case }\end{array}$ & $\begin{array}{l}\text { HEP A04 } \\
\text { Case }\end{array}$ & $\begin{array}{c}\text { CB A06 } \\
\text { Case }\end{array}$ \\
\hline $\begin{array}{l}\text { PEC } \\
{[\mathrm{kWh} / \mathrm{m} 2-\mathrm{y}]}\end{array}$ & 136.69 & 59.11 & 43.89 & 59.54 \\
\hline Improvement & $/$ & $56.76 \%$ & $67.89 \%$ & $56.44 \%$ \\
\hline $\begin{array}{l}\text { Investment } \\
\text { Costs }\left[€ / \mathrm{m}^{2}\right]\end{array}$ & 333.78 & 528.59 & 635.51 & 379.25 \\
\hline $\begin{array}{l}\text { Investment } \\
\text { Cost } \\
\text { Difference }\end{array}$ & $/$ & $58.36 \%$ & $90.39 \%$ & $13.62 \%$ \\
\hline $\begin{array}{l}\text { Global Costs } \\
{\left[€ / \mathrm{m}^{2}\right]}\end{array}$ & 974.09 & 802.6 & 845.24 & 628.3 \\
\hline
\end{tabular}

The same comparison between the settlement with high energy performance buildings and the case of costoptimal buildings connected to a DES can be seen in

\footnotetext{
* Corresponding author: ece.kalaycioglu@o,ozyegin.edu.tr
} 
Table 5. Here, it can be seen also the difference in investment costs. Constructing a settlement with costoptimal energy levels of buildings and connect them to DES will be a more economic investment.

\section{Discussions}

Today, consumed energy throughout the world is still based on fossil sources. Thus, energy, like oil, natural gas, etc., is being transferred from a few producer countries to the consumer ones, which makes the most countries dependent on the external energy sources. Under these circumstances, several nations try to increase their overall energy efficiency to decrease this dependency and related energy expenses by legislative actions, setting long term goals. Additionally, investing in renewable energy sources which can be used locally, help to decrease the energy dependency and to increase energy efficiency, all at once.

Buildings, including both residential and nonresidential ones, are responsible for the one-third of the total primary energy consumption of the world [5]. So, increasing the energy efficiency of the building sector would help to increase the total energy efficiency. In the EU, buildings energy performance directives and related national standards have already become very strict for the buildings to be constructed or renovated to nearly zero energy levels.

At this point, research studies on building energy performance are recently focused on how to carry close the nearly zero energy levels to the cost-optimal levels. Settlement scale energy efficiency measures and district energy systems are inevitably being analysed for this purpose. In this study, it was shown also that district energy systems may carry a settlement with cost-optimal buildings to nearly zero energy levels.

The objection of this paper was to discuss the beneficial and unfavourable points of achieving a very high-performance level at settlement scale. A case study was completed to develop a methodology, but still different cases, such as climates, building types, standards for buildings and DES energy efficiency, should be studied.

The results of the case study showed that the settlement scale studies accelerate the process of achieving a (nearly) zero carbon community. Especially for the newly planned settlements, measures including the location pattern design to control the solar gains, wind effects, increasing the transportation efficiency, decreasing the district heat distribution losses, etc. will assist to reach the desired building energy performance levels. In the EU, NZEB levels are mandatory for all new buildings by 2021 . The results of the case study showed that the DES usage carries the settlement case with cost-optimal buildings to nearly zero energy levels. Although the results should be tested by further studies, DES usage can be seen a potential to close the financial gap between nearly zero energy and cost-optimal levels. Another advantageous point for the settlement scale analyses and energy efficiency measures, larger renewable energy system installations may be utilized, especially for the new settlements. Dependently, more incentives may be obtained for larger scales of renewables, depending on the country-specific conditions.

Settlement scale measures may also be economically beneficial. According to the results, it was already discussed that the settlement with cost-optimal buildings served by a DES has nearly the same PEC with the settlement case with NZEBs, however, have less global cost. Furthermore, when it comes to investment costs, the same case has also less investment cost than the settlement with NZEBs.

Under the DES system, depending on the various combined heat and power system technologies, various energy sources, other than the natural gas and electricity, can be utilized for heating and cooling of the buildings. These sources may be organic wastes, wood chips, or other biomass products. This allows the utilization of the local sources, which decreases fossil fuel consumption, external dependency and energy costs. Also, DES allows being used different system types together which increases the flexibility of the system.

National politics and targets, as they define the boundaries, are very crucial while assessing the effectiveness of the DESs and settlement case measures. The proposed approach of the case study is based on the cost-optimal methodology of EPBD and requires the global cost calculations and nationally-defined nearly zero energy levels. The NZEB should be closely related to national energy targets and politics. In Turkey, NZEB level definitions for different building types and climate conditions are still being discussed and studied. The determination of the NZEB levels would affect the results of this study. Additionally, the regulations on DES are being prepared which will affect the determination of the reference case and pricing mechanisms included in this study.

In the case study, a newly-planned settlement was analysed. However, the conditions may be different for renovating an existing settlement to the required energy performance levels. Beginning with the building level energy efficiency measures, in existing settlements, it cannot be always possible to work on all the buildings in the settlement. Thus, it would take a relatively long period to reach the nearly zero energy targets. The most critical issue for an existing settlement, if no DES system installed already, would be the transformation for the DES system of the buildings. DES placement is important to diminish the distribution losses. Likewise, the building level energy efficiency measures implementations, the transformation of the existing mechanic equipment in all buildings may not be possible. Also, the investment and global costs of these transformations may create a limitation.

According to the case study results, DES connection of buildings was shown as beneficial for energy efficiency and global costs. However, in case of all buildings are forced to be connected to a DES, then monopolization problem may occur. The building owners or managers should have an independence to choose and/or to decide the building conditioning 
system. Some hybrid systems may be developed to allow the usage of both individual and district energy systems.

Additionally, the further legislative actions should be taken by authorities to prevent monopolization problems and also to regulate the high energy performance district energy systems. When the buildings have high energy performances, they require less energy. And this may create an undesirable market for the DES managers.

Lastly, for the further studies, existing settlement refurbishment cases should be analysed to confirm the effectiveness of the proposed methodology. In district energy system alternatives, more efficient cogeneration unit technologies due to alternative energy source usage, such as biomass, wood chips, etc., may be added. More importantly, DES managements and pricing mechanisms should be analysed for a sustainable development.

\section{References}

1. https:/ec.europa.eu/energy/en/topics/energystrategy-and-energy-union, retrieved in November, 2018

2. Directive 2002/91/EC of the European Parliament and of the Council of 16 December 2002 on the energy performance of buildings [EPBD 2002]

3. Directive 2010/31/EU of the European Parliament and of the Council of 19 May 2010 on the energy performance of buildings (recast) [EPBD 2010]

4. Kalaycioglu, E., Yilmaz, A. Z., Energy and Buildings J., A new approach for the application of nearly zero energy concept at district level to reach $E P B D$ recast requirements through a case study in Turkey,EDP Sciences, 152, 680-700 (2017)

5. Cao, X., Dai, X., Liu, J., Energy and Buildings J., Building energy-consumption status worldwide and the state-of-the-art technologies for zero-energy buildings during the past decade, 128, 198-213 (2016) 